\title{
O Custo Aluno-Qualidade Inicial como proposta de justiça federativa no PNE: Um primeiro passo rumo à educação pública de qualidade no Brasil
}

The Quality Student Initial Cost as a federal justice proposed in the PNE: a first step towards the quality of public education in Brazil

El Costo Inicial Estudiante-Calidad como una proposta de justicia federativa en el PNE: un primer paso hacia la calidad de la educación pública en Brasil

Daniel Cara'

\section{Resumo}

Este artigo apresenta o Custo Aluno-Qualidade Inicial (CAQi) como um instrumento voltado a equilibrar o federalismo brasileiro no que se refere à educação básica, e discute como ele se constitui em um dos principais pilares do novo PNE. Para tanto, o trabalho contextualiza o federalismo brasileiro, localizando os problemas da política educacional em meio às desigualdades regionais geradas ou potencializadas pelo modelo de organização do estado nacional brasileiro. O artigo ainda discute os marcos legais e a localização do CAQi neste cenário, e, com isto, advoga-o como uma ferramenta que garante o padrão mínimo de qualidade definido na Constituição Federal. Por fim, o texto apresenta como a questão do CAQi figura no PNE, assim como evidencia como se dará a transição entre o CAQi e o Custo Aluno-Qualidade (CAQ).

Palavras-chave: Custo Aluno-Qualidade Inicial; PNE; Financiamento da Educação; Justiça federativa.

\begin{abstract}
:
This paper presents the Initial Quality Student Cost (CAQi) as an instrument aimed to balance the Brazilian federalism and its effects on the basic education, and discusses how it is one of the main pillars of the new PNE. Therefore, the work contextualizes the Brazilian federalism, locating the problems of education policy in the context of regional inequalities generated or enhanced by Brazilian national state organizational model. The article also discusses the legal framework and the location of CAQi in this scenario, and, thus, advocates it as a tool that guarantees the quality minimum standard defined in the Federal Constitution. Finally, the text shows how the issue of CAQi figure in the PNE, as well as evidences how will be the transition between CAQi and the Quality Student Cost (CAQ).
\end{abstract}

Keywords: Initial Quality Student Cost; PNE; Education financing; Federative justice.

1 Doutorando na Faculdade de Educação da Universidade de São Paulo (USP), mestre em ciência política (USP), coordenador geral da Campanha Nacional pelo Direito à Educação, membro titular do Fórum Nacional de Educação (FNE) e colunista do canal "Educação" do portal UOL. E-mail: tojeira.cara@gmail.com 


\section{Resumen:}

Este trabajo presenta el Costo Estudiante-Calidad Inicial (CAQi) como un instrumento destinado a equilibrar el federalismo brasileño con respecto a la educación básica, y se analiza la forma en que el CAQi es uno de los principales pilares del nuevo PNE. Por lo tanto, el trabajo contextualiza el federalismo brasileño, la localización de los problemas de la política educativa en medio a las desigualdades regionales generadas o majoradas por el modelo de organización del Estado nacional brasileño. El artículo también analiza el marco legal y la ubicación de CAQi en este escenario, y, por lo tanto, lo defiende como una herramienta que garantiza el estándar mínimo de calidad definido en la Constitución Federal. Por último, el texto muestra cómo CAQi está puesto en el PNE, así como demostra como se dará la transición entre CAQi y el costo-calidad para Estudiantes (CAQ).

Palabras-clave: Costo Estudiante-Calidad Inicial; PNE; Financiamiento de la educación; Justicia Federativa.

\section{Introdução}

A implementação do Custo Aluno-Qualidade Inicial (CAQi) esteve entre os temas mais debatidos pela opinião pública, sociedade civil, pesquisadores, parlamentares e representantes do Poder Executivo Federal no processo de tramitação do novo Plano Nacional de Educação (PNE) no Congresso Nacional.

Este artigo apresenta o mecanismo do Custo Aluno-Qualidade Inicial (CAQi), criado e calculado pela Campanha Nacional pelo Direito à Educação, como um instrumento capaz de tornar mais equilibrado e eficaz o federalismo brasileiro no tocante à oferta de matrículas em educação básica, sendo um dos principais pilares do novo PNE - estabelecido na forma da Lei 13.005/2014.

O objetivo do CAQi é materializar um padrão mínimo de qualidade justo, capaz de promover uma educação que visa "o pleno desenvolvimento da pessoa, seu preparo para o exercício da cidadania e sua qualificação para o trabalho", tal como determina o caput do Art. 205 da Constituição Federal - CF.

Além disso, o CAQi busca garantir a "igualdade de condições para o acesso e permanência na escola", princípio asseverado no primeiro inciso do Art. 206 da CF. Em outras palavras, o que se quer com sua implementação é dar condições para que seja ofertada uma educação plural, emancipadora e justa para todos os brasileiros e brasileiras. Enfim, a educação necessária para um Brasil justo e próspero.

O texto também mostra como a questão do CAQi figura no plano, bem como se dará a transição entre o CAQi e o Custo Aluno-Qualidade.

\section{Contextualização: o federalismo brasileiro, as políticas sociais e a política de educação}

No Brasil, ao longo da história, o debate educacional tem dado crescente destaque à questão federativa. O motivo é simples: o pacto federativo é um dos fatores mais relevantes para o resultado das políticas educacionais (CURY, 2006), pois acaba determinando a organização e a gestão do Estado, gerando enorme impacto na estruturação administrativa e política dos governos e na forma como eles respondem² aos cidadãos (ABRUCIO, 2010).

Para analisar os resultados do federalismo brasileiro na implementação e gestão de políticas sociais, Arretche (2004) realiza um extenso levantamento bibliográfico de política internacional comparada. Segundo as pesquisas sistematizadas pela autora, os estados federativos ao redor do mundo são encarados como propensos a produzir níveis comparativamente mais baixos de gasto social em relação a países unitários, bem como menor abrangência e cobertura dos programas sociais. Tendem, ainda, a tornar mais difíceis os problemas de coordenação dos objetivos das políticas, gerando superposição de competências e competição 
entre os diferentes níveis de governo, dada a relação negativa entre a dispersão da autoridade política e a consistência interna das decisões coletivas. Adicionalmente, em estados federativos, as políticas nacionais tendem a se caracterizar por um mínimo denominador comum, necessário para amenizar o impacto das assimetrias existentes nas federações.

É ocioso frisar que qualquer semelhança com a realidade brasileira não é mera coincidência. As conclusões listadas por Arretche (2004) acabam por compor o elenco de desafios a serem considerados e tratados por todos os estados federados, ainda que em graus diferentes e a partir de pontos de partida distintos.

As heterogeneidades, as trajetórias históricas e o legado cultural de cada país impedem a elaboração de uma fórmula específica que oriente os países federados a estabelecer suas instituições (ABRUCIO, 2010). Contudo, se não é possível implementar um desenho institucional ótimo e universal para as federações, ao menos é conhecido o fator determinante do sucesso ou insucesso de qualquer modelo federativo: a capacidade de coordenação entre os entes federados para a realização de políticas públicas que visem à superação de desigualdades diversas e à correção de assimetrias intrafederativas. Em outras palavras, a qualidade de uma federação depende de sua capacidade de compatibilizar autonomia e interdependência entre os entes federados, necessariamente por meio de direitos e deveres bem definidos, além do estabelecimento de normas e arenas institucionais que, respectivamente, orientem e arbitrem medidas administrativas adequadas e legítimas para o conjunto dos entes federados.

Como as assimetrias intrafederativas, ou simplesmente as desigualdades, é um traço comum de todas as federações, a coordenação entre os entes federados exige o estabelecimento de padrões nacionais de qualidade para as políticas públicas, até mesmo como um esforço de legitimação das iniciativas dos governos federais. Como é muito difícil universalizar em um mesmo território a qualidade da oferta de um serviço público, recorre-se aos padrões mínimos de qualidade, ou ao "mínimo denominador comum" das políticas nacionais destacado pela investigação bibliográfica de Arretche (2004).

Condizente com essa lógica, quando determinou que sua proposta de Custo Aluno-Qualidade (CAQ) era inicial (CAQi), a Campanha Nacional pelo Direito à Educação buscou materializar o padrão mínimo de qualidade da oferta de educação básica no Brasil. Portanto, o CAQi representa apenas um primeiro passo, um ponto de partida, e não pode ser tratado como um patamar suficiente de qualidade da educação, em que pese o fato de que o Brasil esteja distante de concretizá-lo.

OCAQ, por sua vez, representa uma tentativa de superação desse padrão mínimo de qualidade materializado no CAQi, aproximando o Brasil do padrão de investimento praticado pelos países mais desenvolvidos em termos educacionais.

\section{O federalismo brasileiro e a educação}

No caso da educação, há três mecanismos constitucionais que, sendo adequadamente regulamentados e bem articulados entre si, podem garantir uma profícua coordenação federativa, colaborando para o estabelecimento de um modelo de "federalismo cooperativo" no Brasil, tal como propõe Abrucio (2010).

A primeira tarefa para a emergência de um pacto cooperativo seria regulamentar o caput do parágrafo único do art. 23 da CF, que trata da cooperação entre os entes federados.

Art. 23. É competência comum da União, dos Estados, do Distrito Federal e dos Municípios:

$[\ldots]$

V - proporcionar os meios de acesso à cultura, à educação e à ciência;

$[\ldots]$

Parágrafo único. Leis complementares fixarão normas para a cooperação entre a União e os Estados, o Distrito Federal e os Municípios, tendo em vista 0 equilíbrio do desenvolvimento e do bem-estar em âmbito nacional. (Redação dada pela Emenda Constitucional n 53 , de 2006) (grifo nosso). 
A segunda tarefa seria a regulamentação do art. 211 da CF, que, aliás, integra o capítulo da educação da Carta Magna e evidencia a necessidade de materialização do padrão mínimo de qualidade.

Art. 211. A União, os Estados, o Distrito Federal e os Municípios organizarão em regime de colaboração seus sistemas de ensino.

$\S 1^{0} \mathbf{A}$ União organizará o sistema federal de ensino e 0 dos Territórios, financiará as instituições de ensino públicas federais e exercerá, em matéria educacional, função redistributiva e supletiva, de forma a garantir equalização de oportunidades educacionais e padrão mínimo de qualidade do ensino mediante assistência técnica e financeira aos Estados, ao Distrito Federal e aos Municípios; (Redação dada pela Emenda Constitucional $n^{0}$ 14, de 1996).

$\S 2^{\circ}$ Os Municípios atuarão prioritariamente no ensino fundamental e na educação infantil. (Redação dada pela Emenda Constitucional $\mathrm{n}^{0} 14$, de 1996)

$\S 3^{\circ}$ Os Estados e o Distrito Federal atuarão prioritariamente no ensino fundamental e médio. [...] (grifo nosso).

A terceira e última tarefa seria estabelecer o Sistema Nacional de Educação (SNE), disposto no caput do art. 214 da CF. 0 SNE deve ser fruto da síntese da cooperação federativa entre os entes federados (art. 23, parágrafo único) e o regime de colaboração entre os sistemas de ensino (art. 211). Reza a CF que o instrumento legal que articula o SNE é, precisamente, o Plano Nacional de Educação (PNE).

Art. 214. A lei estabelecerá o plano nacional de educação, de duração decenal, com o objetivo de articular o sistema nacional de educação em regime de colaboração e definir diretrizes, objetivos, metas e estratégias de implementação para assegurar a manutenção e desenvolvimento do ensino em seus diversos níveis, etapas e modalidades por meio de ações integradas dos poderes públicos das diferentes esferas federativas [...] (Redação dada pela Emenda Constitucional n 59, de 2009) (grifo nosso).

Embora o texto da CF apresente uma demanda clara, até o momento, nenhuma autoridade política, no geral, ou qualquer ministro da Educação, em particular, soube ou quis convocar e liderar a agenda para regulamentar a cooperação federativa e o regime de colaboração (CARA, 2012), condição obrigatória para o estabelecimento do SNE. Contudo, a importância do tema levou as comissões organizadoras das três conferências educacionais empreendidas desde 2008 - Conferência Nacional de Educação Básica (Coneb-2008), I Conferência Nacional de Educação (Conae-2010) e II Conae (2014) - a enfatizar a construção do SNE como principal desafio a ser superado para o sucesso das políticas públicas educacionais.

\section{Desafios para a implantação do SNE}

A necessidade de estabelecimento do SNE, que deve ser articulado pelo PNE segundo o Art. 214 da CF, advém das inúmeras desigualdades verificadas na República brasileira, continuamente retroalimentadas pela falta de regulamentação dos mecanismos de equilíbrio federativo que integram a Carta Magna, o que acaba por prejudicar demasiadamente a realização das políticas e, consequentemente, a consagração dos direitos sociais, inclusive o direito à educação.

É possível elencar três grandes categorias de desigualdades: a desigualdade regional, a desigualdade federativa horizontal e a desigualdade federativa vertical.

\section{A desigualdade regional}

No tocante a fatores federativos, as desigualdades mais conhecidas no Brasil são as regionais. O Gráfico 1 mostra a desigualdade regional na participação do Produto Interno Bruto (PIB) brasileiro, retratando a flagrante concentração de atividade econômica no Sudeste, desde 1939. 


\section{Gráfico 1 - Participação (em \%) do PIB regional no PIB brasileiro.}

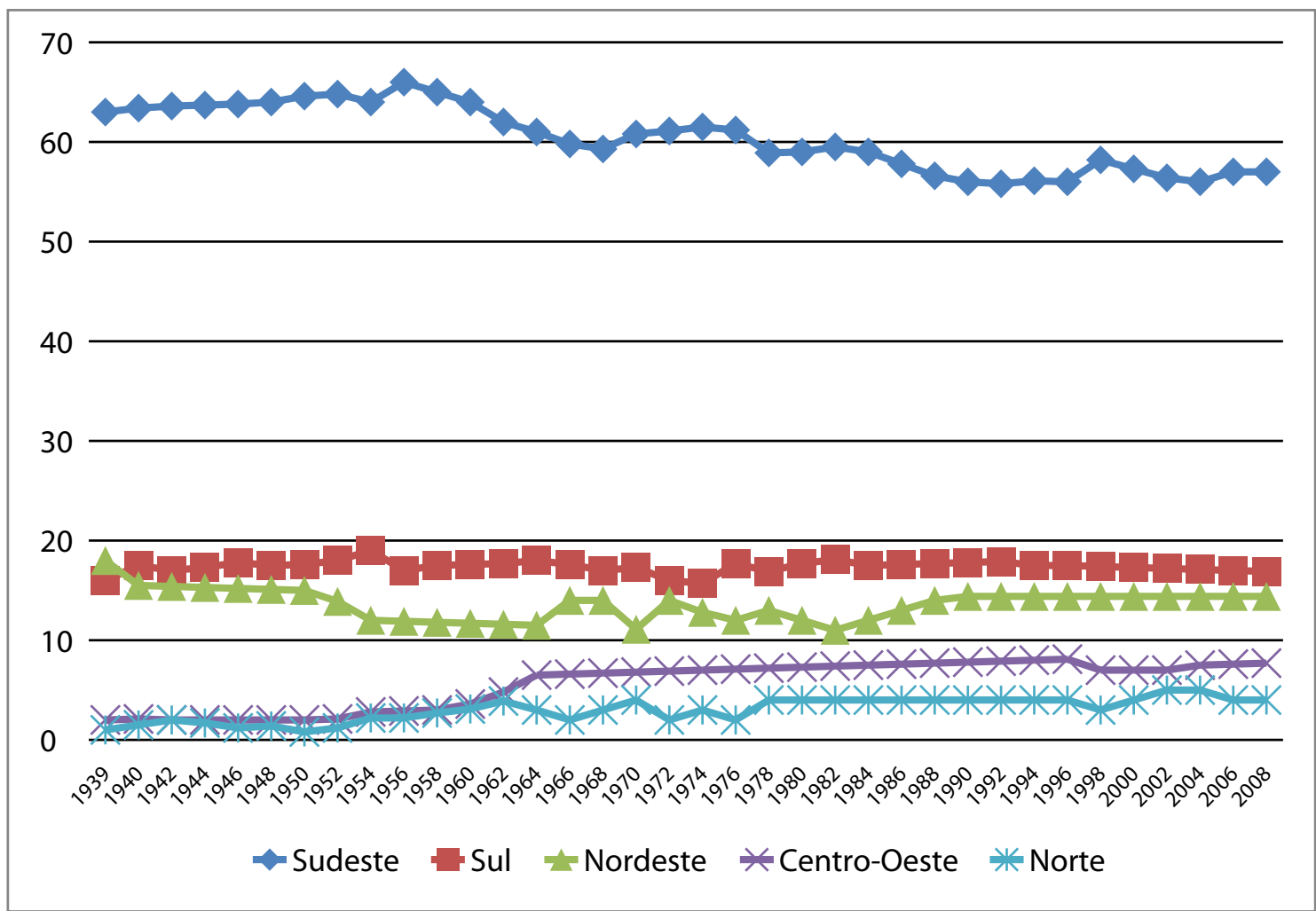

Fonte: Adaptado de Siafi (2008).

\section{A desigualdade federativa horizontal}

Além das desigualdades regionais, há as desigualdades entre os estados, mesmo entre aqueles localizados em uma mesma região e também entre os municípios - inclusive, em relação a cidades localizadas em estados diferentes ou em um mesmo estado. Essa realidade compõe uma espécie de desigualdade federativa horizontal, ou seja, manifesta entre entes subnacionais do mesmo tipo. Em outras palavras, essa categoria compreende as desigualdades entre os estados como pares e também as assimetrias verificadas no conjunto dos municípios entre si.

Em dezembro de 2013, o Instituto Brasileiro de Geografia e Estatística (IBGE) divulgou o estudo "Perfil dos Municípios Brasileiros - 2011". Os resultados da pesquisa demonstram que a geração de riqueza permanece extremamente concentrada no País. Apenas três municípios foram responsáveis por um quinto do PIB brasileiro em 2011, o equivalente a 20,6\% de toda a geração de renda nacional. São eles: São Paulo, Rio de Janeiro e Brasília ${ }^{3}$. Os três primeiros são seguidos por Curitiba, Belo Horizonte e Manaus. O mesmo resultado foi verificado em edição similar da pesquisa, que analisou o ano de 2010. A ordem de importância na geração de riqueza permanece a mesma desde 2008.

Juntos, os seis maiores geradores de riquezas foram responsáveis por $25 \%$ do PIB do Brasil e concentram 13,7\% da população brasileira. Segundo o IBGE - e graças à Zona Franca de Manaus -, com exceção da capital amazonense, onde há equilíbrio entre a participação da indústria de transformação e dos serviços, os outros cinco municípios são concentradores da atividade de "serviços, intermediação financeira, comércio e administração pública". 
Em 2011, apenas São Paulo gerou 11,5\% de toda a renda do País. O Rio de Janeiro foi responsável por uma fatia de 5,1\% do PIB nacional, enquanto Brasília ficou com 4,0\%; Curitiba, com 1,4\%; Belo Horizonte, 1,3\%; e Manaus, 1,0\%. Naquele ano, o país era dividido em 5.565 municípios.

Pela pesquisa também é possível demonstrar as desigualdades entre os estados: São Paulo emplacou nove municípios na lista dos 25 maiores geradores de renda do País. Além da capital paulista, os outros grandes geradores de renda do estado foram: Guarulhos (1,05\% do PIB), Campinas (0,98\%), Osasco (0,95\%), São Bernardo do Campo (0,88\%), Barueri (0,77\%), Santos (0,76\%), São José dos Campos (0,61\%) e Jundiaí (0,53\%). Juntos, os nove municípios paulistas foram responsáveis por $18,04 \%$ do PIB brasileiro.

No conjunto dos 50 maiores geradores de renda, há 15 municípios paulistas, que produziram o equivalente a uma fatia de $20,19 \%$ do PIB. Além dos citados acima estão ainda Ribeirão Preto $(0,45 \%)$, Sorocaba $(0,43 \%)$, Santo André (0,43\%), Diadema (0,28\%), São Caetano do Sul (0,28\%) e Piracicaba (0,28\%).

Já na lista dos cem principais responsáveis pelo PIB de 2011, a participação paulista sobe para 31 municípios, com a presença de Louveira (0,26\%), Taubaté (0,24\%), São José do Rio Preto (0,23\%), Mogi das Cruzes $(0,23 \%)$, Paulínia (0,20\%), Bauru (0,19\%), Sumaré $(0,19 \%)$, Mauá $(0,18 \%)$, Limeira $(0,18 \%)$, Vinhedo $(0,18 \%)$, Cotia $(0,17 \%)$, Americana (0,17\%), Hortolândia (0,16\%), Itapevi (0,15\%), Indaiatuba $(0,14 \%)$ e Cajamar $(0,14 \%)$. Juntos, os 31 municípios paulistas aqui listados responderam por quase um quarto do PIB nacional, o equivalente a $23,2 \%$.

Além disso, a partir dos dados do estudo do IBGE, é possível verificar que a grande maioria dos municípios brasileiros tem gastos públicos maiores do que o que a sua economia gera de tributos, somando as arrecadações municipais, estaduais e federais. No total, apenas 417 cidades brasileiras geram mais dinheiro público do que gastos. E quando se analisa os dados por unidade da federação, é possível entender melhor o perfil dos municípios deficitários e as desigualdades horizontais: oito estados nordestinos estão entre os dez com maior defasagem entre arrecadação municipal e os gastos públicos de seus municípios. Os outros dois são Pará e Rondônia, localizados na Região Norte.

\section{A desigualdade federativa vertical}

Por último, há a desigualdade vertical, sendo esta a menos conhecida, mas certamente a mais representativa em termos federativos globais.

Segundo dados de 2010 do Conselho de Desenvolvimento Econômico e Social da Presidência da República, a União retém 57,1\% dos recursos disponíveis arrecadados, sobrando 24,6\% para os 26 Estados e para o Distrito Federal e apenas 18,3\% para os mais de 5.000 municípios. Contudo, conforme dados de 2009 do Inep (Instituto Nacional de Estudos e Pesquisas Educacionais Anísio Teixeira), órgão vinculado ao MEC (Ministério da Educação), a cada $\mathrm{R} \$ 1$ público investido em políticas educacionais naquele ano, Estados e 0 Distrito Federal despenderam $R \$ 0,41$, os municípios investiram $R \$ 0,39$ e a União colaborou com só $R \$ 0,20$ (CARA, 2012a).

O aspecto dramático das desigualdades federativas brasileiras, em especial a desigualdade vertical, é que as políticas sociais, como resultado da lógica de municipalização, alicerçada pela CF vigente, ficam essencialmente a cargo dos municípios, seja por responsabilização constitucional ou devido à pressão do munícipe sobre o prefeito ou prefeita, o que é territorialmente facilitado. O lema do ex-governador paulista André Franco Montoro pode ter se tornado lugar-comum, mas permanece verdadeiro: "Ninguém vive no Estado ou na União. Eles são figuras jurídicas. Nós vivemos nos municípios." Como também é fato que muitos municípios não gozam de condições para dar conta das demandas que lhe são cobradas.

Como os instrumentos para o federalismo cooperativo não foram, ainda, devidamente regulamentados e articulados, além do próprio fato de os municípios serem desiguais entre si e terem menor capacidade de investimento somado do que o conjunto dos estados e a União, as políticas sociais que dependem da ação dos governos locais tendem a enfrentar maior fragilidade orçamentária, resultando em menor cobertura e pior qualidade.

No caso da educação, o prejuízo mais explícito é o da educação infantil, em especial o direito à creche. O motivo, como reza o $\S 2^{\circ}$ do art. 211 da CF, é que cabe ao município atuar "prioritariamente no ensino 
fundamental e na educação infantil." Dito de outro modo, cabe ao ente federado mais frágil, especialmente em termos orçamentários, custear a etapa mais onerosa de toda a educação básica. Cabe ressaltar que, embora a situação do município seja muito mais complexa, diante de sua baixa arrecadação, também não é fácil para os estados arcarem com os custos do ensino médio.

\section{O CAQi como padrão mínimo de qualidade}

Para determinar uma referência de qualidade no investimento em educação, em 2007, a Campanha Nacional pelo Direito à Educação publicou o livro Custo Aluno-Qualidade Inicial: rumo à educação pública de qualidade no Brasil (CARREIRA; PINTO, 2007), resultado de um estudo inédito conduzido desde 2002.

A partir de insumos como número médio de alunos por turma, pagamento do piso nacional salarial do magistério, política de carreira e de formação continuada aos profissionais da educação, bibliotecas e salas de leitura, laboratórios de ciências, laboratórios de informática, quadras poliesportiva cobertas, brinquedotecas para todas as creches, pré-escolas e escolas dos anos iniciais do ensino fundamental e garantia de recursos para o desenvolvimento de projetos pedagógicos - o Custo Aluno-Qualidade Inicial (CAQi) aponta quanto deve ser investido anualmente por aluno de cada etapa da educação básica para que o Brasil comece a oferecer uma educação (e uma escola) pública com um padrão mínimo de qualidade, materializando a demanda disposta no $\S 1^{\circ}$ do art. 211 da CF, que obriga uma participação mais efetiva da União.

Em termos práticos, o CAQi propõe uma inversão da lógica que rege hoje a definição dos orçamentos públicos para a educação no País, pois parte do que é necessário para garantir a educação com um padrão mínimo de qualidade e não do que está disponível no orçamento. O estudo do CAQi foi a base da Nota Técnica "Por que 7\% do PIB para a educação é pouco? Cálculo dos investimentos adicionais necessários para o novo PNE garantir um padrão mínimo de qualidade" (CAMPANHA NACIONAL PELO DIREITO À EDUCAÇÃO, 2011)4, até o momento o principal documento produzido pela sociedade civil para questionar o patamar de investimento de $7 \%$ do PIB, proposto pelo MEC, como meta de financiamento do novo Plano Nacional de Educação (PNE). Essa Nota Técnica foi analisada pelo Ipea em três publicações: no Comunicado nº 124 (2011), no livro Brasil em desenvolvimento 2011: Estado, Planejamento e Políticas Públicas (2012a) e no Políticas Sociais: acompanhamento e análise (2012b).

\section{O CAQi e o marco legal brasileiro}

Historicamente, a participação da União no financiamento das políticas sociais está muito aquém de seu poder arrecadatório e de sua capacidade de investimento. Relembrando uma citação anterior, segundo dados do Inep, em 2009, a cada $R$ \$ 1 público investido em educação pública, o governo federal aplicou apenas $R$ \$ 0,20. Em 2012 a situação piorou. Novamente, conforme dados do Inep, de cada R\$1 público investido em educação pública, o governo federal colocou $\mathrm{R} \$ 0,18$. Os estados e o Distrito Federal aplicaram, em conjunto, $R \$ 0,40$. Já os municípios investiram $R \$ 0,42 .{ }^{5}$

Ou seja, o ente federado que mais arrecada, possuidor de mais da metade da receita tributária líquida, é aquele que menos contribui com as políticas públicas educacionais. Inversamente, o que menos arrecada, é o que mais investe em educação.

Sendo problema antigo, o tema é tratado objetivamente no $\S 1^{\circ}$ do art. 211 da CF: a União deve exercer, em matéria educacional, "função redistributiva e supletiva, de forma a garantir equalização de oportunidades

4 A referida Nota Técnica foi produzida por mim e por Luiz Araújo, doutor em educação pela Faculdade de Educação da Universidade de São Paulo e expresidente do Instituto de Políticas Educacionais Anísio Teixeira (Inep).

5 Os dados de 2012 só foram divulgados após requerimento de informação apresentado pelo Senador Randolfe Rodrigues (Psol-AP). 
educacionais e padrão mínimo de qualidade do ensino mediante assistência técnica e financeira aos estados, ao Distrito Federal e aos municípios."

\section{O legislador e o padrão mínimo de qualidade}

Ciente de que as desigualdades existentes na federação brasileira são herança, entre outros fatores, do desenvolvimento assimétrico da economia nas diversas regiões e estados do país, e que a União arrecada muito mais do que os demais entes federados, o legislador estabeleceu que caberia a ela o papel de diminuir as desigualdades federativas. Tal ação deveria ser feita via redistribuição de recursos, por meio de medidas como foi o Fundef ${ }^{6}$ e é atualmente o Fundeb ${ }^{7}$, ambos no caso da educação.

Como as desigualdades são muito gritantes e os custos das regiões brasileiras são díspares, o legislador determinou que a função supletiva e redistributiva da União deve ter como pressuposto um padrão mínimo de qualidade nacional $^{8}$, como um atributo de cidadania e justiça federativa. Em outras palavras, independentemente de onde esteja residindo a cidadã ou o cidadão, toda brasileira ou brasileiro deve ter assegurado seu direito à educação pública com base em um patamar básico de qualidade.

Essa referência pretende reduzir as desigualdades nacionais, tal como dispõe o inciso I do Art. 206 da Constituição Federal: "Art. 206. O ensino será ministrado com base nos seguintes princípios: I - igualdade de condições para o acesso e permanência na escola; [...] (grifo nosso)".

Como dito anteriormente, foi como um exercício de definição objetiva do padrão mínimo de qualidade na educação básica que a Campanha Nacional pelo Direito à Educação coordenou os esforços coletivos que culminaram na formulação do mecanismo do CAQi (Custo Aluno-Qualidade Inicial). Pragmaticamente, a Campanha também buscou mensurar os custos da demanda gerada pelo inciso IX do Art. $4^{\circ}$ da Lei de Diretrizes e Bases da Educação Nacional (LDB, Lei 9.394/1996).

Art. $4^{0} 0$ dever do Estado com educação escolar pública será efetivado mediante a garantia de: (...)

IX - padrões mínimos de qualidade de ensino, definidos como a variedade e quantidade mínimas, por aluno, de insumos indispensáveis ao desenvolvimento do processo de ensino-aprendizagem. (grifo nosso)

Após diversas rodadas de consulta e negociação, que envolveram dezenas de pesquisadores, gestores e servidores públicos, sindicalistas, ativistas, professores e outros educadores, pais e estudantes, a Campanha Nacional pelo Direito à Educação concluiu uma primeira versão do CAQi, expressa concretamente pela a lista e a precificação dos insumos necessários para a garantia do padrão mínimo de qualidade para cada etapa e modalidade da educação básica.

Em 5 de maio de 2010, o Conselho Nacional de Educação (CNE) aprovou o Parecer CNE/CEB n 8, de 2010, que normatiza os padrões mínimos de qualidade da educação básica nacional de acordo com o CAQi. O parecer resulta do Termo de Cooperação firmado entre a Câmara de Educação Básica do CNE e a Campanha Nacional pelo Direito à Educação em 5 de novembro de 2008, o primeiro estabelecido entre o Conselho e uma organização da sociedade civil. Contudo, o parecer aguarda homologação por parte do MEC ${ }^{9}$ desde então.

Aprovado nos documentos finais de todas as conferências de educação, como ferramenta basilar do SNE, a viabilização do CAQi impõe a necessidade de materialização da função redistributiva e supletiva da União na educação básica.

6 Fundef é o Fundo de Manutenção e Desenvolvimento do Ensino Fundamental e de Valorização do Magistério. Foi instituído pela Emenda Constitucional n. ${ }^{0} 14$, de setembro de 1996, e regulamentado pela Lei $n .{ }^{\circ}$ 9.424, de 24 de dezembro do mesmo ano, e pelo Decreto $n^{0} 2.264$, de junho de 1997.

7 Fundeb é o Fundo de Manutenção e Desenvolvimento da Educação Básica e de Valorização dos Profissionais da Educação. Foi criado pela Emenda Constitucional $n^{0}$ 53/2006 e regulamentado pela Lei $n^{0}$ 11.494/2007 e pelo Decreto n ${ }^{0}$ 6.253/2007, em substituição ao Fundef, que vigorou de 1998 a 2006.

80 piso nacional salarial do magistério, regulamentado pela Lei 11.738/2008 é familiar à ideia de padrão mínimo de qualidade ou de "mínimo denominado comum" das políticas nacionais, relembrando Arretche (2004).

9 Poderiam ter homologado o CAQi os ex-ministros Fernando Haddad e Aloizio Mercadante. 
Para mensurar essa medida de justiça federativa, inúmeras metodologias poderiam ser trilhadas. Em Nota Técnica ${ }^{10}$ recente, a Associação Nacional dos Pesquisadores em Financiamento da Educação (Fineduca), optou por calcular a necessidade de participação financeira da União a partir do melhor mecanismo federativo vigente na educação: o Fundeb. Este sistema de 27 fundos estaduais financia toda a educação básica - a creche até o ensino médio, considerando todas as modalidade - e foi construído por meio de forte interação entre o Poder Público e a sociedade civil (MARTINS, 2011) ${ }^{11}$.

Em termos práticos, segundo o ordenamento normativo atual, o CAQi é uma referência comparativa à definição dos valores mínimos do Fundeb, que não correspondem a um padrão mínimo de qualidade. Tanto é assim que menos de $1 \%$ das escolas brasileiras têm infraestrutura mínima segundo os critérios do CAQi (SOARES NETO, 2013), sendo que além da infraestrutura das escolas, o mecanismo considera muitos outros insumos, como remuneração dos profissionais, número de alunos por turma, etc.

Para a realização da estimativa de demanda da participação da União na educação básica, primeiro foi levantado o número de matrículas de cada etapa e modalidade contabilizadas em cada um dos 27 fundos estaduais do Fundeb, conforme o Censo Escolar de 2011. Posteriormente, as matrículas foram multiplicadas pelo valor corrente do CAQi-2012. Os resultados dessa longa operação está sintetizada no Quadro 1.

\section{Quadro 1. Valores de referência do CAQi (2012)}

\begin{tabular}{|c|c|c|}
\hline & Fonte/cálculo & Valor (R\$) \\
\hline Creche (tempo integral) & CAQi & $8.288,28$ \\
\hline Creche (tempo parcial & CAQi + Fundeb* & $5.097,29$ \\
\hline Pré-escola (tempo integral) & CAQi + Fundeb ${ }^{*}$ & $4.171,77$ \\
\hline Pré-escola (tempo parcial) & CAQi & $3.209,05$ \\
\hline Ensino Fundamental Anos Iniciais - Urbano & CAQi & $3.060,29$ \\
\hline Ensino Fundamental Anos Finais - Urbano & CAQi & $2.996,53$ \\
\hline Ensino Fundamental Anos Iniciais - Rural & CAQi & $5.057,98$ \\
\hline Ensino Fundamental Anos finais - Rural & CAQi & $3.867,86$ \\
\hline Ensino Fundamental Tempo Integral & CAQi + Fundeb ${ }^{*}$ & $3.978,38$ \\
\hline Ensino Médio Urbano & CAQi & $3.081,54$ \\
\hline Ensino Médio Rural & CAQi (EF II Rural) & $3.867,86$ \\
\hline Ensino Médio Tempo Integral & CAQi + Fundeb & $3.337,31$ \\
\hline Ensino Médio integrado à Ed. Profissional & CAQi + Fundeb & $3.337,31$ \\
\hline Educação Especial & CAQi & $6.120,50$ \\
\hline Educação de Jovens e Adultos & CAQi & $3.060,29$ \\
\hline EJA (integrada à Educação Profissional) & CAQi + Fundeb & $3.672,35$ \\
\hline Educação Indígena e Quilombola & CAQi (EF I Rural) & $5.057,98$ \\
\hline Creches conveniadas (tempo integral) & CAQi + Fundeb & $7.011,88$ \\
\hline Creches conveniadas (tempo parcial) & CAQi + Fundeb & $5.097,29$ \\
\hline Educação Especial (instituições conveniadas) & CAQi + Fundeb & $6.120,58$ \\
\hline
\end{tabular}

Fonte: Fineduca, 2013.

Obs: * Nesses casos, em que o Parecer CEB/CNE no 8/2010 não estabeleceu um valor para o CAQi, usou-se o valor por aluno do CAQi para a etapa correspondente o fator de ponderação do Fundeb.

Nota: Os valores do CAQi levaram em conta o Parecer CEB/CNE nº 8/2010 e o PIB per capita de 2011 (R\$ 21.252,00).

10 Publicada em setembro de 2013, esta Nota Técnica foi produzida pelo Prof. Dr. José Marcelino Rezende Pinto (USP/Ribeirão Preto e presidente da Fineduca) e contou com a minha colaboração e de Luiz Araújo.

11 Por sua bem-sucedida incidência na construção e regulamentação do Fundeb, a Campanha Nacional pelo Direito à Educação foi agraciada em 2007 com Prêmio Darcy Ribeiro, concedido pela Câmara dos Deputados. 
Em seguida, a Nota Técnica apresenta o cálculo da complementação atual da União ao Fundeb em comparação com o valor que deveria ter sido destinado ao fundo para viabilizar o CAQi em $2012^{12}$ (Tabela 1).

Tabela 1. Estimando complementação da União ao CAQi, com base no Fundeb por Fundo Estadual. Ano: 2012, tendo por base a matrícula de 2011.

\begin{tabular}{|c|c|c|c|c|c|}
\hline \multirow{4}{*}{$\begin{array}{l}\text { Fundo Estadual } \\
\text { por Unidade da } \\
\text { Federaçãa }\end{array}$} & \multicolumn{2}{|c|}{ Fundeb atual } & \multirow[b]{2}{*}{ C } & \multicolumn{2}{|c|}{ Fundeb com CAQi } \\
\hline & A & B & & D & $E=(D-C)$ \\
\hline & $\begin{array}{c}\text { Recursos do } \\
\text { Fundeb aportados } \\
\text { por Estados e } \\
\text { Municípios (previsão } \\
\text { 2012) }\end{array}$ & \begin{tabular}{c}
\multicolumn{2}{c}{ Complemento da } \\
União via Fundeb \\
(previsão 2012)
\end{tabular} & $\begin{array}{l}\text { Total de Recursos } \\
\text { dos Fundos } \\
\text { Estaduais do Fundeb }\end{array}$ & $\begin{array}{l}\text { Recursos } \\
\text { necessários para a } \\
\text { garantia do CAQi via } \\
\text { Fundeb }\end{array}$ & $\begin{array}{c}\text { Complemento } \\
\text { adicional da União } \\
\text { para viabilizar o } \\
\text { CAQi }\end{array}$ \\
\hline & (previsão 2012) & (previsão 2012) & (previsão 2012) & (base 2012) & (base 2012) \\
\hline$A C$ & 638.251 .462 & $\mathrm{~N} / \mathrm{A}$ & 638.251 .462 & 892.533 .114 & 254.281 .652 \\
\hline $\mathrm{AL}$ & 1.682.374.140 & 398.860 & 1.682 .773 .000 & 2.946.708.335 & 1.263 .935 .335 \\
\hline AM & 2.146 .581 .209 & 286.529 & 2.146.867.738 & 3.693.269.631 & 1.546.401.893 \\
\hline AP & 602.612 .554 & $\mathrm{~N} / \mathrm{A}$ & 602.612 .554 & 714.731 .646 & 112.119 .092 \\
\hline $\mathrm{BA}$ & 7.009.382.532 & 2.264 .033 & 7.011 .646 .565 & 12.442 .932 .699 & 5.431 .286 .134 \\
\hline $\mathrm{CE}$ & 3.986 .443 .436 & 1.110 .954 & 3.987 .554 .390 & 6.957 .956 .638 & 2.970 .402 .248 \\
\hline ES & 2.369 .896 .327 & $\mathrm{~N} / \mathrm{A}$ & 2.369 .896 .327 & 2.747.184.091 & 377.287 .764 \\
\hline G0 & 3.001.324.965 & $\mathrm{N} / \mathrm{A}$ & 3.001.324.965 & 3.986 .494 .123 & 985.169 .158 \\
\hline MA & 4.014.974.338 & 2.080 .903 & 4.017 .055 .241 & 7.194.889.337 & 3.177 .834 .096 \\
\hline$M G$ & 9.190 .477 .730 & $\mathrm{~N} / \mathrm{A}$ & 9.190 .477 .730 & 14.239 .418 .434 & 5.048 .940 .704 \\
\hline MS & 1.524.423.065 & $N / A$ & 1.524 .423 .065 & 2.185 .997 .448 & 661.574 .383 \\
\hline MT & 1.654 .640 .284 & $\mathrm{~N} / \mathrm{A}$ & 1.654 .640 .284 & 2.792.431.074 & 1.137 .790 .790 \\
\hline PA & 4.470.574.217 & 2.214 .575 & 4.472.788.792 & 7.968.943.025 & 3.496.154.233 \\
\hline PB & 1.748 .284 .744 & 154.254 & 1.748 .438 .998 & 3.074.561.866 & 1.326 .122 .868 \\
\hline $\mathrm{PE}$ & 3.989.960.495 & 530.611 & 3.990 .491 .106 & 6.828 .064 .711 & 2.837 .573 .605 \\
\hline $\mathrm{PI}$ & 1.673.862.453 & 399.655 & 1.674.262.108 & 2.964.219.788 & 1.289.957.680 \\
\hline $\mathrm{PR}$ & 5.046 .513 .944 & $\mathrm{~N} / \mathrm{A}$ & 5.046 .513 .944 & 7.991.725.526 & 2.945 .211 .582 \\
\hline $\mathrm{RJ}$ & 6.444 .668 .573 & $N / A$ & 6.444 .668 .573 & 9.434 .468 .136 & 2.989 .799 .563 \\
\hline RN & 1.516 .644 .774 & N/A & 1.516 .644 .774 & 2.625.726.952 & 1.109.082.178 \\
\hline Ro & 964.490 .586 & $\mathrm{~N} / \mathrm{A}$ & 964.490 .586 & 1.469 .084 .135 & 504.593 .549 \\
\hline $\mathrm{RR}$ & 425.147 .268 & $\mathrm{~N} / \mathrm{A}$ & 425.147 .268 & 463.824 .317 & 38.677 .049 \\
\hline RS & 5.727.395.131 & $N / A$ & 5.727.395.131 & 7.189.126.056 & 1.461 .730 .925 \\
\hline $\mathrm{SC}$ & 3.427 .561 .011 & $\mathrm{~N} / \mathrm{A}$ & 3.427 .561 .011 & 4.725.302.780 & 1.297.741.769 \\
\hline SE & 1.131 .140 .034 & $N / A$ & 1.131 .140 .034 & 1.708 .260 .222 & 577.120 .188 \\
\hline $\mathrm{SP}$ & 25.903 .591 .684 & $\mathrm{~N} / \mathrm{A}$ & 25.903 .591 .684 & 29.129 .817 .811 & 3.226 .226 .127 \\
\hline TO & 997.087 .938 & $\mathrm{~N} / \mathrm{A}$ & 997.087 .938 & 1.331 .546 .398 & 334.458 .460 \\
\hline TOTAL & 101.288 .304 .893 & 9.440 .374 .000 & 110.728 .678 .893 & 147.699 .218 .292 & 36.970 .539 .399 \\
\hline
\end{tabular}

Fontes: Para as estimativas do Fundeb e matrículas por etapa e modalidade: Portaria Interministerial $\mathrm{n}^{0} 1.809$ de 28/12/2011; Para os valores do CAQi: Quadro 1. 
Como resultado, apenas considerando-se as matrículas atuais, se faz necessária a transferência global de mais de $\mathrm{R} \$ 46,10$ bilhões de reais da União para os Estados, Distrito Federal e Municípios, via o sistema de fundos do Fundeb. Ou seja, os atuais $\mathrm{R} \$$ 9,4 bilhões acrescidos de $\mathrm{R} \$ 36,9$ bilhões. Este valor é quase o quádruplo da previsão da complementação da União para 2012 e seria o volume capaz de garantir o cumprimento do texto constitucional e da LDB, a partir do padrão mínimo de qualidade mensurado pelo CAQi.

Assim, conforme os dados apresentados na Tabela 1, todos os fundos estaduais do Fundeb deveriam receber complementação da União, não apenas nove, como ocorreu em 2012. Somente se quase quintuplicasse sua participação no âmbito do Fundeb é que o governo federal estaria cumprindo integralmente com sua obrigação estabelecida no $\S 1^{\circ}$ do art. 211 da CF, contribuindo efetivamente para reduzir as desigualdades regionais e assegurar padrão mínimo de qualidade de ensino.

$\mathrm{Na}$ análise da Tabela 1 chama a atenção o fato de que mesmo o fundo do Fundeb de São Paulo receberia complementação da União. Isso ocorre por uma razão simples: o valor por aluno para creche no Fundeb está absolutamente abaixo de qualquer relação com o custo real desta etapa. Como o número de matrículas em creche é relativamente alto em São Paulo, se comparado com o restante do país, surge a demanda por recursos adicionais. O mesmo vale para a educação do campo.

O baixo comprometimento da União na educação básica, entre outros prejuízos, tem inviabilizado o cumprimento da Lei do Piso Nacional Salarial do Magistério (Lei 11.738/2008) por parte de muitos entes federados, em especial naquelas regiões mais pobres do país, nas quais o Fundeb é a fonte quase exclusiva de recursos educacionais. Paralelamente a isso, observa-se um incremento das chamadas transferências voluntárias pelo governo federal, ou a gestão baseada em programas. Isso tem obrigado os gestores estaduais e municipais a se submeterem às políticas definidas em Brasília para conseguir alguns parcos recursos para melhorar a educação ofertada por suas administrações. Assim, recria-se uma espécie de nova política de balcão, que estimula práticas pouco cidadãs, atrasando o desenvolvimento da democracia brasileira (NOBRE, 2013).

\section{Necessidade de alterações no Fundeb}

Embora possa ser considerada uma medida insuficiente de coordenação federativa, caso o Fundeb seja fortalecido à luz de maior participação da União como mensura a Nota Técnica da Fineduca, o Brasil daria um grande passo rumo ao fortalecimento da educação básica como um todo.

Nesse sentido, uma emenda da Campanha Nacional pelo Direito à Educação, aprovada por unanimidade na plenária final da I Conae necessita ser transformada em Lei:

b) Alterar a lei do Fundeb no sentido de retirar o sistema de balizas que limitam os fatores de ponderação do fundo a uma escala de 0,7 a 1,3. Esta medida é imprescindível para substituir a atual perspectiva do gasto-aluno/a/ano ou custo-aluno/a/ano existente no fundo, por uma política de custo-aluno/a-qualidade. Concomitantemente, a complementação da União ao Fundeb deve avançar imediatamente para uma transferência equivalente a 1\% do PIB/ano. (BRASIL, 2010b, p. 114).

Ao propor a retirada do sistema de balizas ${ }^{13}$, o objetivo é viabilizar o correto investimento em creches - que, segundo o estudo do CAQi, custa mais do que o dobro do investimento necessário no ensino fundamental anos iniciais - uma vez que as balizas impõem um teto de diferenciação de apenas $30 \%$ para o valor da matrícula para essa etapa. Contudo, apenas a retirada do sistema de balizas não resolve o problema. Como visto anteriormente, é preciso incluir um novo volume de recursos no conjunto do fundo. Desse modo, a emenda propõe que a contribuição da União avance de cerca de $\mathrm{R} \$ 10$ bilhões para $\mathrm{R} \$ 46$ bilhões, adicionado mais de $\mathrm{R} \$ 36,9$ bilhões de dinheiro novo, tal como visto na Tabela 1.

13 As balizas determinam que os valores de todas as etapas e modalidades da educação básica devem ser, no mínimo, 70\% do valor do ensino fundamental anos iniciais (urbano) e, no máximo, 30\% maior do que essa etapa de referência. 0 sistema de balizas, de certo modo, é uma herança do Fundef que só investia no ensino fundamental. 


\section{O CAQi como instrumento de equidade}

Os indicadores educacionais disponíveis, captados pelos exames nacionais de desempenho, pelo censo escolar, pelo censo populacional e pelas pesquisas nacionais de amostragem domiciliar, atestam de forma inequívoca que os esforços até então implementados não foram eficazes para aproximar as condições de oferta educacional dos municípios e estados mais pobres daqueles registrados pelas regiões mais ricas do país, reforçando via a educação as gritantes desigualdades nacionais.

Em 2012, a União Nacional dos Dirigentes Municipais de Educação (Undime) lançou o estudo Perfil dos Gastos Educacionais nos Municípios Brasileiros - Ano Base 2009, com o cálculo do custo real de cada etapa da educação básica empreendida pelos municípios brasileiros. No Gráfico 2, a comparação entre o CAQi e o custo-aluno/ano praticado na região Nordeste, segundo o estudo mencionado, mostra o quanto essa região está distante de alcançar o padrão mínimo de qualidade do ensino, especialmente na educação infantil.

Gráfico 2 - Comparação do custo-aluno/ano da região Nordeste e o CAQi (2009).

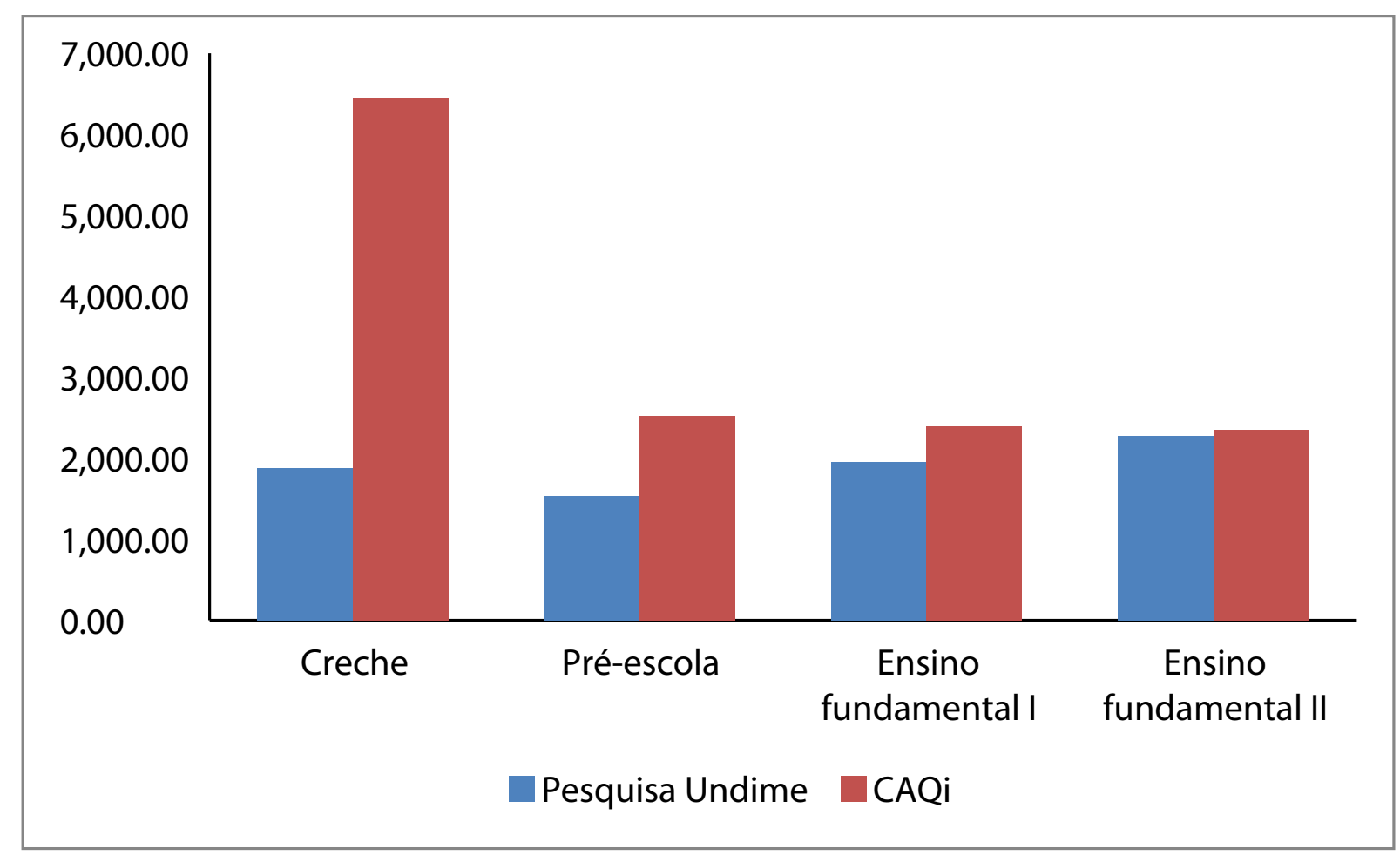

Fonte: Adaptado de Undime (2012) e Campanha Nacional pelo Direito à Educação (2011).

O mecanismo do CAQi é um primeiro passo no longo caminho de melhoria da escola pública no Brasil. Em termos práticos, além de obrigar um primeiro nível de justiça federativa na matéria educacional, sua implementação atenderia também a uma parte importante da demanda calculada pela Campanha Nacional pelo Direito à Educação em sua Nota Técnica (2011), que aponta o custo do novo PNE. Conforme o estudo, para cumprir com as metas do novo plano, garantindo padrão de qualidade tanto para as matrículas atuais quanto para aquelas que precisam ser criadas na educação básica e na educação superior, o Brasil deve investir um patamar equivalente a 10,4\% do PIB em educação pública até o décimo ano do novo plano. Essa demanda é sintetizada na Tabela 2. 


\section{Tabela 2 - Custo adicional do novo PNE.}

\begin{tabular}{|c|c|c|c|}
\hline \multirow{2}{*}{ Categoria } & $\begin{array}{c}\text { Cálculos da Campanha } \\
\text { Nacional pelo Direito à } \\
\text { Educação (R\$) }\end{array}$ & Cálculos do MEC (R\$) & Diferença \\
\cline { 2 - 4 } & $\mathrm{A}$ & $\mathrm{B}$ & $\mathrm{C}=(\mathrm{B}-\mathrm{A})$ \\
\hline Educação infantil & $23.656 .775 .160,00$ & $9.683 .635 .930,00$ & $13.973 .139 .230,00$ \\
\hline Ensino médio & $3.643 .905 .000,00$ & 0 & $3.643 .905 .000,00$ \\
\hline Educação especial & $3.589 .867 .120,00$ & 0 & $3.589 .867 .120,00$ \\
\hline Educação em tempo integral & $23.964 .400 .000,00$ & $3.766 .240 .130,06$ & $20.198 .159 .869,94$ \\
\hline Educação de Jovens e Adultos (EJA) & $21.256 .661 .768,20$ & 0 & $21.256 .661 .768,20$ \\
\hline Educação profissionalizante & $5.927 .954 .879,12$ & $4.456 .014 .000,00$ & $1.471 .940 .879,12$ \\
\hline Educação superior & $45.266 .181 .400,00$ & $15.203 .801 .874,83$ & $30.062 .379 .525,17$ \\
\hline Formação docente & $9.258 .894 .000,00$ & $923.023 .365,76$ & $8.335 .870 .634,24$ \\
\hline Remuneração docente & $33.265 .961 .706,57$ & $27.025 .805 .706,30$ & $6.240 .156 .000,27$ \\
\hline TOTAL & $169.830 .601 .033,89$ & $61.058 .521 .006,95$ & $108.772 .080 .026,94$ \\
\hline \% PIB - 2009* & $5,4 \%$ & $1,9 \%$ & $3,5 \%$ \\
\hline
\end{tabular}

Fonte: Campanha Nacional pelo Direito à Educação, 2011.

* Aqui é apresentado o custo adicional. Segundo o Inep, em 2009, o Brasil investiu 5\% do PIB em educação pública. Portanto, a meta de investimento do novo PNE deve ser de 10,4\% do PIB, segundo a Campanha Nacional pelo Direito à Educação.

Utilizar o CAQi para fortalecer o Fundeb, exigindo maior participação da União no financiamento da educação básica, não é o caminho definitivo para consagrar o direito à educação no Brasil, nem para resolver toda a regulamentação do SNE. Mas pode ser uma referência e um importante e pragmático primeiro passo no enfrentamento das desigualdades federativas brasileiras, melhorando em curto prazo a qualidade da oferta das mais de 40 milhões de matrículas públicas de educação básica que hoje existem no País.

Pontualmente, com a implementação do CAQi, todos os professores que lecionam receberiam pelo menos o piso salarial e teriam 1/3 de sua jornada dedicada ao planejamento de aulas. Concomitantemente, todos os profissionais da educação teriam política de carreira e formação continuada. Além disso, o número de alunos por turma seria adequado e todas as unidades escolares teriam infraestrutura suficiente para a promoção da relação de ensino-aprendizagem, tal como determina a LDB e demandam os artigos 205 e 206 da CF.

Sem dúvida, trata-se de uma boa introdução a uma reivindicação imprescindível já apresentada neste texto: efetivar um investimento equivalente a 10\% do PIB em educação pública até o décimo ano de vigência do PNE, conforme mensura a Nota Técnica da Campanha Nacional pelo Direito à Educação (2011).

Isso é necessário porque implementar o CAQi via Fundeb representa um acréscimo de 1,06\% do PIB no investimento direto em educação básica pública no Brasil. No entanto, aumentar o padrão de qualidade das atuais matrículas de educação básica é insuficiente, pois há 3,7 milhões crianças e adolescentes de 4 a 17 anos fora da escola (UNICEF \& CAMPANHA, 2012), 14 milhões de analfabetos e 3,4 milhões de matrículas em creche precisam ser criadas nos próximos 10 anos (CAMPANHA, 2011). Portanto, é preciso avançar.

Assim, além dos $R \$ 46$ bilhões de reais que a União deve transferir para estados e municípios para o cumprimento do padrão mínimo de qualidade mensurado pelo CAQi, com R\$36,9 bilhões de recursos novos, é preciso insistir no cumprimento das metas do novo PNE. Uma simulação da distribuição dos recursos da educação, por nível de ensino, pode ser vista no Gráfico 3. 
Gráfico 3. Investimento em educação por nível realizado em 2009 versus Custo do PNE II, segundo a Campanha Nacional pelo Direito à Educação, em R\$

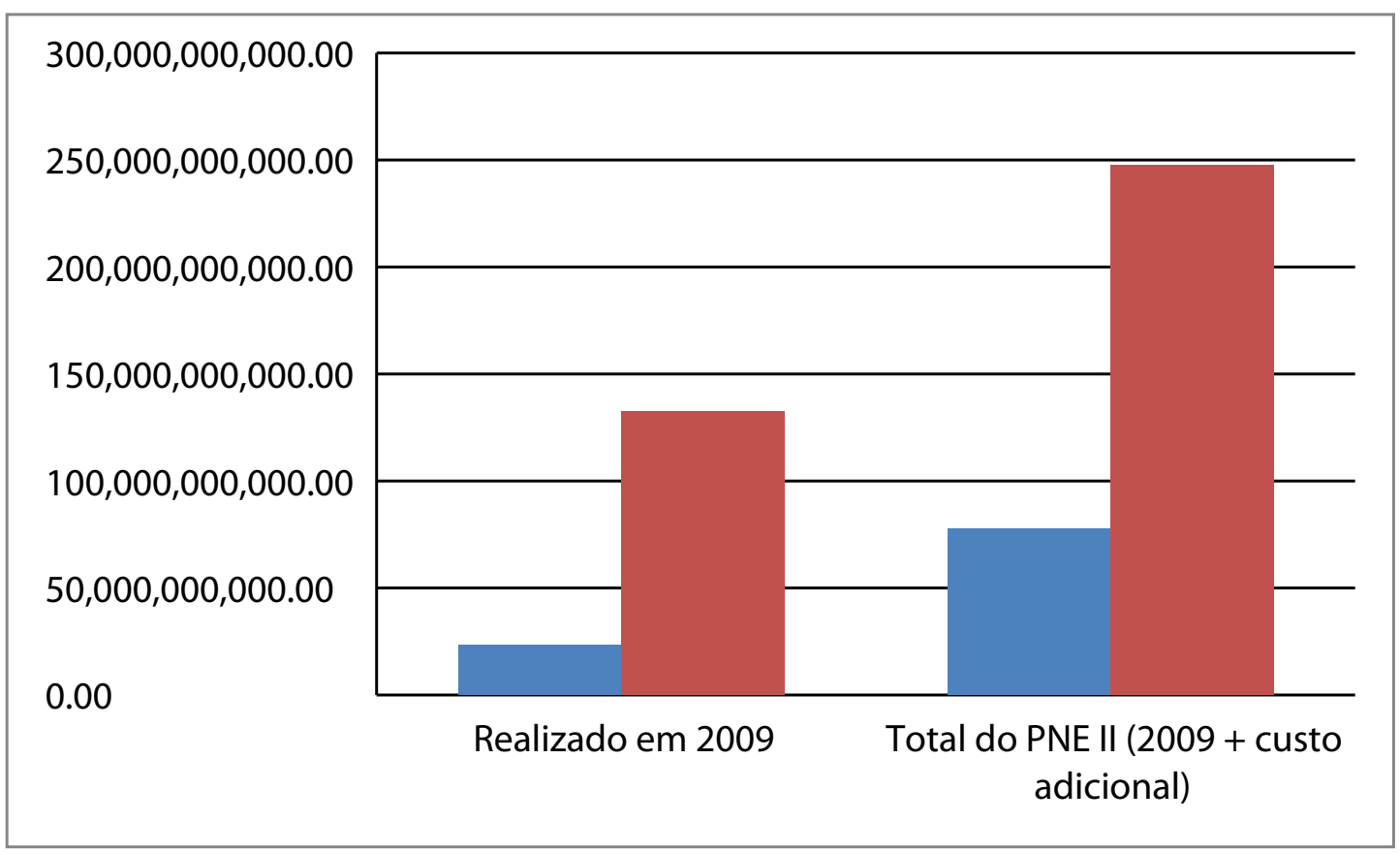

Fonte: Campanha Nacional pelo Direito à Educação (2011).

Em outras palavras, se em 2011 somente a educação básica pública contou com um investimento equivalente a 4\% do PIB (Inep, 2014), a implementação do CAQi - via um justo aumento da complementação da União ao Fundeb - faria com que somente este nível de ensino recebesse um investimento próximo de 4,84\% do PIB. Contudo, para o cumprimento de todas as metas do PNE relativas à educação básica, o Brasil preciso avançar para um patamar equivalente a $8 \%$ do PIB. Essa é a agenda nacional prioritária, considerando que aumentar o financiamento das políticas públicas educacionais é condição necessária, ainda que insuficiente, para a consagração plena do direito à educação - que compreende, necessariamente, acesso e padrão de qualidade, materializado no CAQ.

\section{CAQi e CAQ no PNE}

O novo PNE, na forma da Lei 13.005/2014, faz precisamente esta transição entre o CAQi e o CAQ, estabelecendo um prazo de dois anos para a implementação plena do CAQi, que deve ser idealmente empreendida pelas alteração no Fundeb supracitadas.

No texto original de PNE, elaborado pelo Ministério da Educação, o tema era abordado da seguinte maneira: "20.5) Definir o custo aluno-qualidade da educação básica à luz da ampliação do investimento".

No final, graças à bem-sucedida incidência da Campanha Nacional pelo Direito à Educação na Câmara dos Deputados e a compreensão adquirida pelo relator da matéria na casa, Deputado Angelo Vanhoni, a questão do CAQi e do CAQ ficaram do seguinte modo:

20.5) desenvolver, por meio do Instituto Nacional de Estudos e Pesquisas Educacionais Anísio Teixeira - INEP, estudos e acompanhamento regular dos investimentos e custos por aluno da educação básica e superior pública, em todas as suas etapas e modalidades;

20.6) no prazo de 2 (dois) anos da vigência deste PNE, será implantado o Custo Aluno-Qualidade inicial - CAQi, referenciado no conjunto de padrões mínimos estabelecidos na legislação educacional e cujo financiamento será calculado com base nos respectivos 
insumos indispensáveis ao processo de ensino-aprendizagem e será progressivamente reajustado até a implementação plena do Custo Aluno Qualidade - CAQ;

20.7) implementar o Custo Aluno Qualidade - CAQ como parâmetro para o financiamento da educação de todas etapas e modalidades da educação básica, a partir do cálculo e do acompanhamento regular dos indicadores de gastos educacionais com investimentos em qualificação e remuneração do pessoal docente e dos demais profissionais da educação pública, em aquisição, manutenção, construção e conservação de instalações e equipamentos necessários ao ensino e em aquisição de material didático-escolar, alimentação e transporte escolar;

20.8) o CAQ será definido no prazo de 3 (três) anos e será continuamente ajustado, com base em metodologia formulada pelo Ministério da Educação - MEC, e acompanhado pelo Fórum Nacional de Educação - FNE, pelo Conselho Nacional de Educação - CNE e pelas Comissões de Educação da Câmara dos Deputados e de Educação, Cultura e Esportes do Senado Federal;

20.9) regulamentar o parágrafo único do art. 23 e 0 art. 211 da Constituição Federal, no prazo de 2 (dois) anos, por lei complementar, de forma a estabelecer as normas de cooperação entre a União, os Estados, o Distrito Federal e os Municípios, em matéria educacional, e a articulação do sistema nacional de educação em regime de colaboração, com equilíbrio na repartição das responsabilidades e dos recursos e efetivo cumprimento das funções redistributiva e supletiva da União no combate às desigualdades educacionais regionais, com especial atenção às regiões Norte e Nordeste

20.10) caberáà União, na forma da lei, a complementação de recursos financeiros a todos os Estados, ao Distrito Federal e aos Municípios que não conseguirem atingir o valor do CAQi e, posteriormente, do CAQ.

Como resultado, em dois anos, além de iniciar a busca pelo padrão mínimo de qualidade materializado com o CAQi, a distribuição federativa de recursos ficará mais justa, tal como confirma o Gráfico 4, abaixo.

Gráfico 4. Projeção da participação do investimento direto em educação, por ente federado (2012), com a implementação da Estratégia 20.10 do PNE.

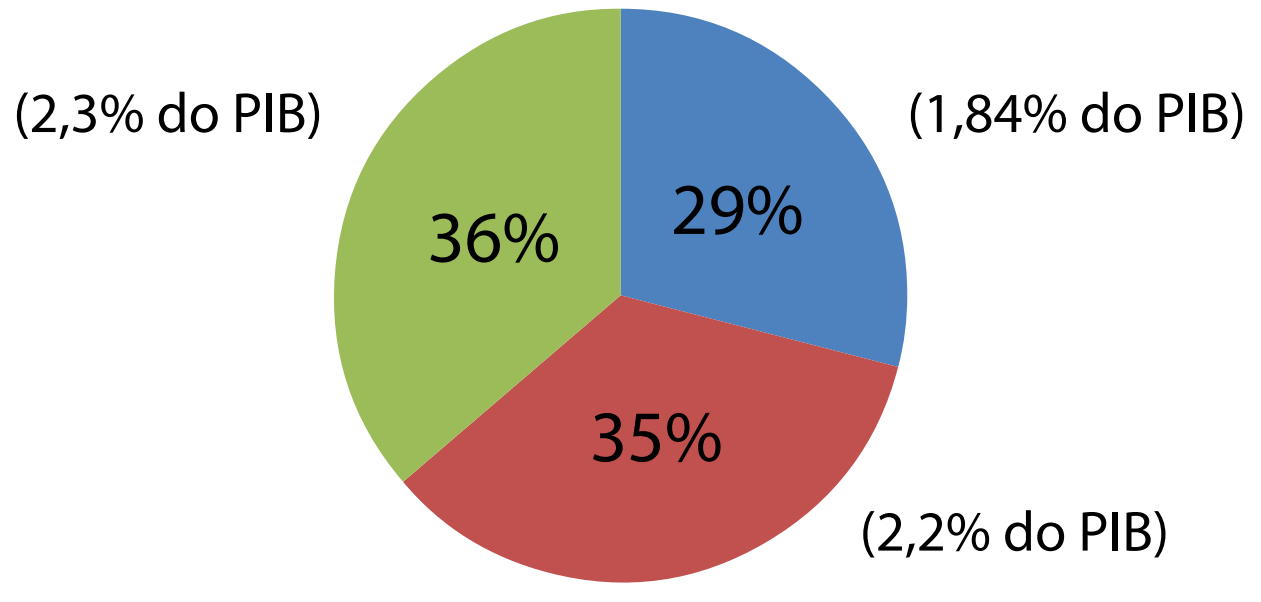

-União "Estados e DF "Municípios

Fonte: Adaptado de Inep (2014). 


\section{Referências}

ABRUCIO, F. L. A dinâmica federativa da educação brasileira: diagnóstico e propostas de aperfeiçoamento. In: OLIVEIRA, R. P.; SANTANA, W. (Orgs.). Educação e federalismo no Brasil: combater desigualdades, garantir a diversidade. Brasília, DF: Unesco, 2010, p. 39-70.

ARAUJO, G. C. Município, federação e educação: história das instituições e das ideias políticas no Brasil. 2005. Tese (Doutorado em Educação) - Faculdade de Educação, Universidade de São Paulo, São Paulo, 2005. ARRETCHE, M. Federalismo e políticas sociais no Brasil: problemas de coordenação e autonomia. São Paulo em Perspectiva, São Paulo, v. 18, n. 2, p. 17-26, abr./jun. 2004. Disponível em: <http://dx.doi.org/10.1590/S010288392004000200003 >. Acesso em: 14 de maio de 2012.

ASSOCIAÇÃO NACIONAL DE PESQUISADORES EM FINANCIAMENTO DA EDUCAÇÃO. Por que a União deve complementar o CAQi no PNE? Disponível em: <http:// http://www.redefinanciamento.ufpr.br/nota1_13. pdf $>$. Acesso em: 13 de dezembro de 2014.

BRASIL. Constituição (1988). Constituição da República Federativa do Brasil. Brasília, DF: Senado Federal, 1988.

. Lei n ${ }^{\circ}$ 9.394, de 20 de dezembro de 1996. Estabelece diretrizes e bases da educação nacional. Diário Oficial da União, Brasília, DF, 23 dez. 1996.

. Lei n 10.172, de 9 de janeiro de 2001. Aprova o Plano Nacional de Educação e dá outras providências. Diário Oficial da União, Brasília, DF, 10 jan. 2001.

Lei no 11.494, de 20 de junho de 2007. Regulamenta o Fundo de Manutenção e Desenvolvimento da Educação Básica e de Valorização dos Profissionais da Educação - FUNDEB, de que trata o art. 60 do Ato das Disposições Constitucionais Transitórias; altera a Lei $n^{\circ}$ 10.195, de 14 de fevereiro de 2001; revoga dispositivos das Leis nos 9.424, de 24 de dezembro de 1996, 10.880, de 9 de junho de 2004, e 10.845, de 5 de março de 2004; e dá outras providências. Diário Oficial da União, Brasília, DF, 21 jun. 2007b.

Emenda Constitucional $n^{\circ}$ 59, de 11 de novembro de 2009. Acrescenta $\S 3^{\circ}$ ao art. 76 do Ato das Disposições Constitucionais Transitórias para reduzir, anualmente, a partir do exercício de 2009, o percentual da Desvinculação das Receitas da União incidente sobre os recursos destinados à manutenção e desenvolvimento do ensino de que trata o art. 212 da Constituição Federal, dá nova redação aos incisos I e VII do art. 208, de forma a prever a obrigatoriedade do ensino de quatro a dezessete anos e ampliar a abrangência dos programas suplementares para todas as etapas da educação básica, e dá nova redação ao $\S 4^{\circ}$ do art. 211 e ao $\S 3^{\circ}$ do art. 212 e ao caput do art. 214, com a inserção neste dispositivo de inciso VI. Diário Oficial da União, Brasília, DF, 12 nov. 2009.

Ministério da Educação. Conselho Nacional de Educação. Parecer CNE/CEB n 8, de 5 de maio de 2010. Estabelece normas para aplicação do inciso IX do artigo $4^{\circ}$ da Lei n 9.394/96 (LDB), que trata dos padrões mínimos de qualidade de ensino para a Educação Básica pública. Ministério da Educação, 2010a. Disponível em: $\quad<$ http://portal.mec.gov.br/index.php?option=com_docman\&task=doc_download\&gid=5368\&ltemid=>. Acesso em: ago. 2012.

Ministério da Educação. Conferência Nacional de Educação. Construindo o sistema nacional articulado de educação: o Plano Nacional de Educação, diretrizes e estratégias; documento final. Brasília, DF: MEC, $2010 b$.

Instituto Nacional de Estudos e Pesquisas Educacionais Anísio Teixeira. Indicadores Financeiros

Educacionais. Brasília, DF: 2014.

CAMPANHA NACIONAL PELO DIREITO À EDUCAÇÃO. Nota técnica - por que 7\% do PIB para a educação é pouco? Cálculo dos investimentos adicionais necessários para o novo PNE garantir um padrão máximo de qualidade. São Paulo, 2011. 
CARREIRA, D.; PINTO, J. M. R. Custo aluno-qualidade inicial: rumo à educação pública de qualidade no Brasil. São Paulo: Global; Campanha Nacional pelo Direito à Educação, 2007.

CARA, D. Mais dinheiro federal na educação básica. Sessão Tendências e Debates. Folha de S. Paulo: São Paulo. 03 de fevereiro de 2012a.

Municípios no pacto federativo: fragilidades sobrepostas. Revista Retratos da Escola, Brasília, v. 6, n. 10, p. 255-273, jan./jun. 2012b.

CURY, C. R. J. Federalismo político e educacional. In: FERREIRA, Naura Syria Carapeto (Org.). Políticas públicas e gestão da educação: polêmicas, fundamentos e análises. Brasília, DF: Líber Livro, 2006.

ESTADOS UNIDOS DA AMÉRICA. Constituição (1789). Constituição dos Estados Unidos da América. Washington, D.C.: Convenção Constitucional, 1978.

FEDERAÇÃO DAS INDÚSTRIAS DO ESTADO DO RIO DE JANEIRO (FIRJAN). Índice FIRJAN de Gestão Fiscal (IFGF). Rio de Janeiro, 2012. Disponível em: <http://www.firjan.org.br/IFGF/>. Acesso em: 1 de maio de 2012.

HAMILTON, A.; MADISON, J.; JAY, J. O federalista. Brasília, DF: Editora Universidade de Brasília, 1984.

INSTITUTO BRASILEIRO DE GEOGRAFIA E ESTATÍSTICA. Perfil dos Municípios Brasileiros - 2011. Rio de Janeiro, 2013. Disponível em: http://www.ibge.gov.br/home/estatistica/economia/perfilmunic/2011/default.shtm. Acesso em: 13 de fevereiro de 2013.

INSTITUTO NACIONAL DE ESTUDOS E PESQUISAS EDUCACIONAIS ANÍSIO TEIXEIRA (INEP). Sinopse estatística da educação básica: censo escolar 2006. Brasília, DF, 2007.

INSTITUTO DE PESQUISA ECONÔMICA APLICADA (IPEA). № 124 - Financiamento da educação: necessidades e possibilidades. Comunicados do Ipea, Brasília, DF, 14 dez. 2011. Disponível em: <http:// www.ipea.gov.br/portal/images/stories/PDFs/comunicado/111214_comunicadoipea124.pdf>. Acesso em: 1 de maio de 2012.

Brasil em desenvolvimento 2011: Estado, planejamento e políticas públicas. Brasília, DF, 2012a.

Políticas sociais: acompanhamento e análise. n. 20. Brasília, DF, 2012b. Disponível em: <http:// www.ipea.gov.br/portal/images/stories/PDFs/politicas_sociais/bps_20_completo.pdf>. Acesso em: 1 de maio de 2012.

LIMONGI, F. P. "O federalista": remédios republicanos para males republicanos. In: WEFFORT, Francisco (Org.). Os clássicos da política. 14. ed. São Paulo: Ática, 2006, p. 243-287.

MARTINS, P. de S.. Fundeb, federalismo e regime de colaboração. Campinas: Autores Associados, 2011. MONTESQUIEU, C. L. O espírito das leis. Genebra: Barrillot, 1750.

NOBRE, M. Choque de democracia - Razões da revolta. Companhia das Letras (edição Digital), 2013.

SOARES NETO, J. J.; JESUS, G. R.; KARINO, C. A.; ANDRADE, D. F. Uma escala para medir a infraestrutura escolar. Est. Aval. Educ, 2013. vol.24, n.54, pp. 78-99.

UNIÃO NACIONAL DOS DIRIGENTES MUNICIPAIS DE EDUCAÇÃO (UNDIME). Relatório de pesquisa perfil dos gastos educacionais nos municípios brasileiros - ano base: 2009. Brasília, DF, 2012.

UNICEF. CAMPANHA NACIONAL PELO DIREITO À EDUCAÇÃO. Relatório de pesquisa - Fora da escola não pode. Brasília, DF, 2012.

Recebido em Agosto de 2014 - Aprovado em Outubro de 2014 